\title{
Methods to Relieve Heat Stress for Florida Dairies ${ }^{1}$
}

\author{
I. M. Toledo, G. E. Dahl, R. A. Bucklin, and D. K. Beeke²
}

Florida's hot and humid weather affects dairy cattle performance throughout the year. The key to understand and prevent the negative effects of heat stress is to understand when heat stress begins.

Heat stress occurs when the heat produced by a dairy cow's biological processes and the heat absorbed from the environment exceeds the capacity of the cow to lose heat, which results in physiological changes to decrease heat load in the body (Figure 1).

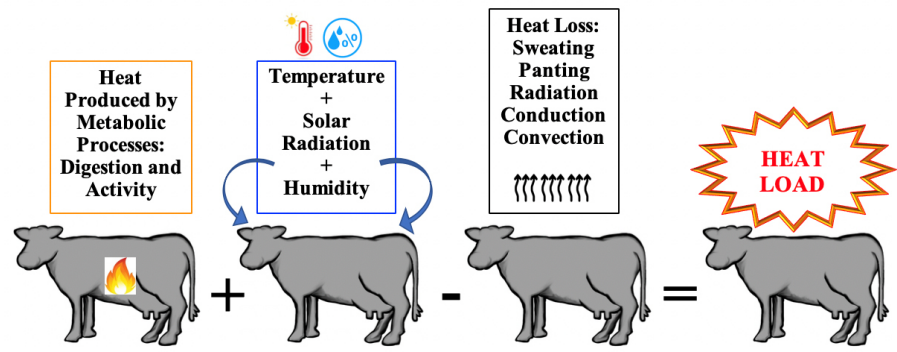

Figure 1. Heat stress in dairy cows.

The negative effects of heat stress in both lactating and dry cows are well documented. Exposure of lactating cows to heat stress results in decreased feed intake, altered metabolism, reduced milk production, impaired reproductive performance, and increased incidence of disease. Additionally, dry cows exposed to heat stress have decreased milk production in the subsequent lactation, as well as decreased immune responses and comparatively poor reproductive performance.
A cow loses heat through its skin surface and respiratory tract. Physiological signs of heat stress in dairy cows consist of increases in respiration rate, body temperature (usually rectal or vaginal measurements), water intake, sweating, and salivation. As the temperature humidity index (THI) increases, cows' respiration and sweating rates rise. When the cow can no longer cool itself with respiration and sweating, panting and increased standing time occurs in an attempt to maintain normal body temperature. It is important to understand the physiological changes caused by heat stress in order to implement cooling practices that are effective in minimizing the negative effects of heat stress (Figure 2).

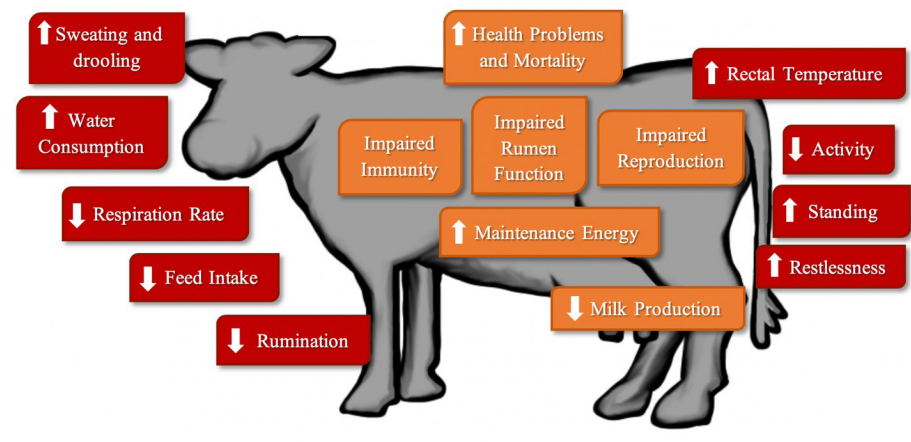

Visible Signs of Heat Stress

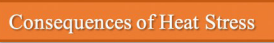

Figure 2. Visible signs and consequences of heat stress in dairy cows.

1. This document is CIR782, one of a series of the Department of Agricultural and Biological Engineering, UF/IFAS Extension. Original publication date November 1991. Revised January 1992, July 2002, and February 2019. Visit the EDIS website at https://edis.ifas.ufl.edu for the currently supported version of this publication.

2. I. M. Toledo, regional specialized Extension agent II, dairy, UF/IFAS Extension Northeast District; G. E. Dahl, professor, Department of Animal Sciences; R. A. Bucklin, professor, Department of Agricultural and Biological Engineering; UF/IFAS Extension, Gainesville, FL 32611; and D. K. Beeke, professor, Department of Animal Scinces Michigan State University.

The Institute of Food and Agricultural Sciences (IFAS) is an Equal Opportunity Institution authorized to provide research, educational information and other services

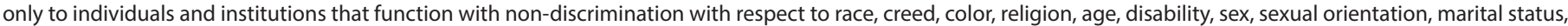

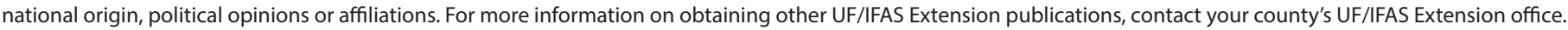
U.S. Department of Agriculture, UF/IFAS Extension Service, University of Florida, IFAS, Florida A \& M University Cooperative Extension Program, and Boards of County Commissioners Cooperating. Nick T. Place, dean for UF/IFAS Extension. 
The temperature humidity index has been used to estimate exposure to heat stress in dairy cattle. However, when animals are housed in open lots and directly exposed to the sun, the THI underestimates heat stress because it does not take into consideration the effects of solar radiation. A THI of less than 71 is described as a thermal comfort zone for dairy cows, 72 to 79 as mild heat stress, 80 to 90 as moderate heat stress, and greater than 90 as severe heat stress. More recently, it has been documented that high-producing cows begin to be negatively affected by heat stress at a THI value as low as 68. Increases in THI are associated with decreased lying time and increased standing and water intake (Table 1).

Table 1. Relationship between THI, heat stress level, and body responses such as respiration rate and rectal temperature.

\begin{tabular}{|c|l|c|l|}
\hline THI & Heat Stress Level & $\begin{array}{l}\text { Respiration } \\
\text { Rate }(\mathbf{b p m})\end{array}$ & $\begin{array}{l}\text { Cow Rectal } \\
\text { Temperature }\end{array}$ \\
\hline $68-71$ & Mild & $>60$ & $101.3^{\circ} \mathrm{F}\left(38.5^{\circ} \mathrm{C}\right)$ \\
\hline $72-79$ & Mild to Moderate & $>75$ & $102.2^{\circ} \mathrm{F}\left(39^{\circ} \mathrm{C}\right)$ \\
\hline $80-89$ & Moderate to Severe & $>85$ & $104^{\circ} \mathrm{F}\left(40^{\circ} \mathrm{C}\right)$ \\
\hline$>90$ & Severe & $>100$ & $106^{\circ} \mathrm{F}\left(41^{\circ} \mathrm{C}\right)$ \\
\hline
\end{tabular}

The most practical methods to alleviate the negative effects of heat stress on dairy cattle can be grouped into three main areas, shade, ventilation, and cooling. These methods can be used alone or in any combination. They are most effective when located in areas of high heat stress. Common areas that will benefit are feed barns, loading areas, and holding areas. Cows must be provided with adequate quantities of drinking water at all times but particularly when conditions are likely to cause heat stress. Changes in feed management can help cows avoid the negative effects of heat stress.

\section{Shade}

Shade can be either natural or artificial. When cows are kept outside, in most cases the best method for relieving heat stress is natural shade in the form of shade trees. When not enough natural shade is available, artificial shades can provide needed shelter from the effects of solar radiation. Several factors should be considered when constructing shades. The orientation of shade structures is very important. During the summer, a higher percentage of shadow lies under a shade structure with an east-west orientation than under a structure with a north-south orientation. During the winter, the amount of floor that is sunlit for drying is about the same. If you want the driest possible conditions for non-confined situations, a north-south orientation with a large fenced-in area is best.

If the cows are to be confined under a shade structure, it should be oriented east-west. Each cow should be provided with 40 to 60 square feet of shade. The floor should be four-inch concrete grooved to provide firm footing. It should be sloped about $1.5 \%$ to $2 \%$ for proper operation of flush systems. Earthen floors under shades quickly can become mud holes in Florida and so are not generally recommended. If earth floors are used, the structure should be located on a well-drained location, such as a mound. If cows are not confined under the shade, the concrete slab needs to be larger than the area of the shade roof. This is because the orientation of the sun varies with the season and even with an east-west orientation, the shadow will not always be entirely under the structure. The slab should extend 8 feet on the north side, and 20 feet on the east and west sides if the eave height is 12 feet. Higher eaves will require that the slab be extended further. In Florida, the shade pattern will fall on the south side only in the early morning and late afternoon, so the slab does not need to be extended to the south.

Several factors influence the selection of shade structure height. Air movement under the shade is increased as eave height is increased, but the cost of the structure also increases with height, and the shade pattern moves more with tall structures. The recommended eave height in Florida is 12 feet for structures up to 40 feet wide. Structures wider than 40 feet should have eave heights of at least 14 feet. The site of the shade structure should provide at least 50 feet of clearance on each side between adjacent buildings, trees, or other obstructions. Gable roofs should have a continuous open ridge as shown in Figure 3 to promote natural ventilation.

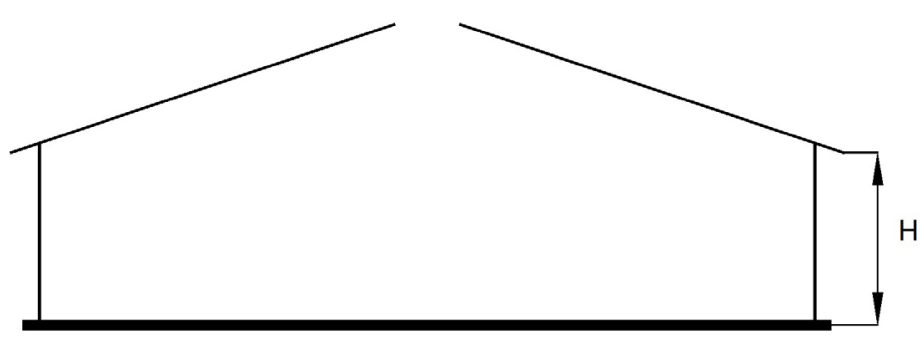

$\mathrm{H}=12$ FEET FOR WIDTH LESS THAN 40 FEET $\mathrm{H}=14$ FEET FOR WIDTH GREATER THAN 40 FEET

Figure 3. Shade structure.

The most effective shade roof is an aluminum or white colored galvanized metal roof with about one inch of insulation directly beneath the metal roofing. The insulation reduces the radiation heat load on the cows but can cause problems if birds or other pests establish themselves in the insulation and damage the material. The top surface of the roof should be painted white to reflect solar radiation. 
Shade cloth can be used as the material for shade roofs. These cloths are available in patterns providing $30 \%$ to $90 \%$ shade and fabricated from a variety of yarn materials. The most common material used for animal shades is woven polypropylene fabric providing $80 \%$ shade. Knitted and non-woven materials are entering the market, and some show promise for use as shade cloth. Shade cloth is considerably less expensive than solid roofing material but does not provide as much protection from solar radiation as a solid roof. The fabric tension must be tightened whenever you notice slack in the shade cloth, or it will quickly be torn apart by the wind.

To achieve the most benefit from the shade structure, put feed and water for the cows under the shade. Plan a waste-management system as an integral part of the shade structure. Waste can be removed by scraping or flushing. Even if flushing is not feasible right away, it is still a good idea to design the slab for flushing so that a flush system can be added easily at some later time.

\section{Air Movement}

An important factor in the relief of heat stress is air movement. Air movement can be natural or forced. Air movement can reduce the temperature in a building or under a shade structure to that of the outside air. A ventilation system that provides at least one air change per minute is recommended.

Many agricultural buildings can be ventilated adequately by natural means. Natural ventilation is caused by two effects. The first is air movement caused by breezes moving through open sides of sidewall vents. The second is air movement caused by thermal buoyancy. This also is referred to as the stack or chimney effect. Air enters the structure through side or eave vents, is heated, and then rises and exits through a ridge vent. This method is effective even on a totally still day. It is not effective in a building with sidewalls. The air movement caused by thermal buoyancy in a building without sidewalls will occur at the eave height, not at animal level. Air movement at eave height will reduce the roof temperature and thus the radiation load on the cows, so it is still beneficial. The stack effect is most effective in structures with steep roofs and large ridge vents. Roof slopes between 4:12 and 6:12 are the most effective. Roofs with slopes of less than 4:12 often leak and don't have enough slope to generate a good stack effect. Roofs steeper than 6:12 will still have a good stack effect but are expensive to construct and difficult to work on.
Ridge vents in Florida should be at least one foot wide plus two inches for each ten feet of structure width over twenty feet. A vent functions best when it is totally open without a cap. If a cap is necessary, the eave of the cap should have at least one foot of clearance between it and the roof peak. Most commercially available ridge vents are undersized for Florida conditions. Several ridge vent types are illustrated in Figure 4. Overshot designs are not recommended. Under most conditions, they reduce rather than promote air flow through a structure. If a flat or nearly flat roof is desired, a ridge vent will be of little benefit if the structure is less than 40 feet wide. Buildings with flat roofs with widths greater
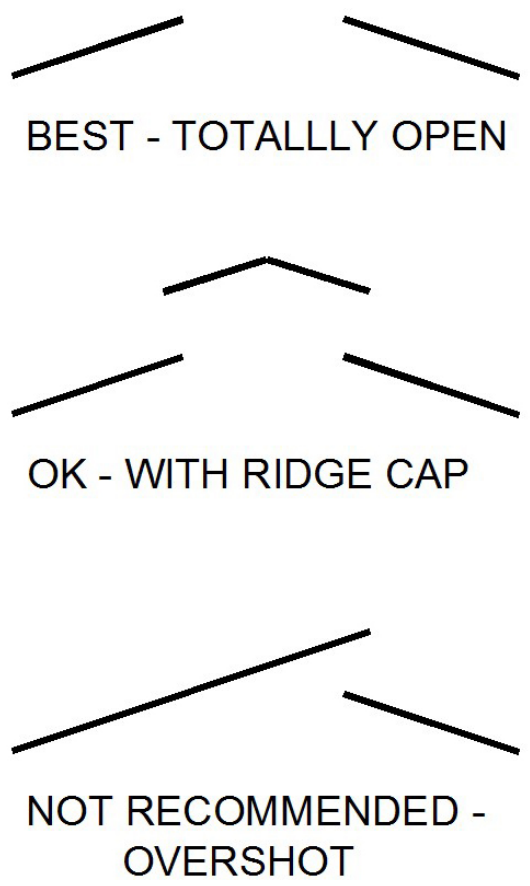

Figure 4. Ridge vent types.

than forty feet may benefit from ridge vents or openings in the roof but will probably require mechanical ventilation to be satisfactory.

\section{Cooling}

Summer conditions in Florida require cooling below ambient temperatures for optimum production. There are several methods available that can reduce air temperatures below outside ambient temperatures. The most familiar is mechanical air conditioning or refrigeration. This method generally is too expensive to use with livestock operations.

A more economical method is evaporative cooling. Evaporative cooling works by using energy from the air to evaporate water. This lowers the temperature of the air and raises its relative humidity. Evaporative cooling is most effective in areas of low humidity. However, even in muggy Florida, daytime humidities are low enough to allow for 
beneficial cooling to occur when the air temperatures are the highest.

Evaporative cooling methods can be grouped into mist, fog, and sprinkling systems. The difference between a mist and a fog system is in droplet size. A mist droplet is larger than a fog droplet and will drop slowly to the floor, evaporating as it falls. A fog particle stays suspended in the air and evaporates before it touches the ground. Fog systems are very efficient methods of cooling air but also are more expensive than mist systems and require more mainte-

nance. A mist or fog system that sprays small water droplets into the air cools the air as the droplets evaporate. When an animal inhales the cooled air, it can exchange heat with the air and remove heat from its body. This type of system can be effective, but is difficult to use under windy conditions or in combination with fans. If a misting system does not wet the hair coat to the skin, an insulating layer of air can be trapped between the skin and the layer of water. This effect can cause a harmful heat buildup. Cooling studies involving mist systems also have reported respiratory and pneumonia problems when cows were exposed to mist or fog particles for long periods of time. Systems in which the cow inhales cool air from an air duct have been tested with some success but are expensive.

An alternative to mist and fog systems is the sprinkling system. This method does not attempt to cool the air, but instead uses a large droplet size to wet the hair coat and skin of the cow, and then water evaporates and cools the hair and skin. This allows the cow to lose heat more effectively through its skin.

Sprinkling systems are most effective when combined with air movement. This combination promotes evaporation of water from the skin and hair coat. An effective cooling system for a two-row freestall barn would include fans over the freestalls and a sprinkler line over the cow feedline. The recommendation for a four-row freestall barn includes fans over both the freestalls and a feedline sprinkling system. Air velocity of 400 to 600 cubic feet per minute (cfm) per 1,400 -pound cow is recommended. At least one 36-inch fan for each forty animals is needed to provide this velocity. Each fan should provide an airflow of about 1,000 cfm/ stall. A fan of this size will move air effectively for about 10 diameters or 30 feet. Other fan sizes also can be used. In modern cooling systems, fans are activated when ambient temperatures reach $70^{\circ} \mathrm{F}$ and animals are soaked for one and a half minutes at five-minute intervals when ambient temperatures are above $72^{\circ} \mathrm{F}$. A typical cooling system is shown in Figure 5. The fans should be located as low as possible above the height necessary for cow and equipment clearance. Sprinklers should be located immediately below the fans so that the water is thrown just under the bottom of the fans. If the fans blow water onto areas that must be kept dry, they should be shut off when the sprinklers are activated. This can be done by using a double-pole switch to control both the fans and water pump. The nozzles selected to sprinkle the desired flow rate should operate at a low pressure such as 10 psi so that the water droplets will stay in the desired area. An amount of water equal to 0.05 inches of rainfall should be applied during each sprinkling. Take care when using mist, fog, or sprinkling systems that the nozzles do not become clogged. Trash and minerals in the

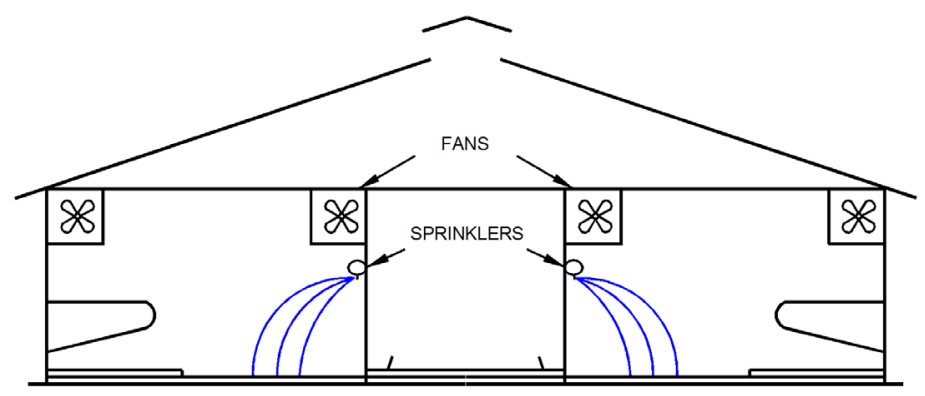

Figure 5. Fans and sprinklers.

water can be harmful to pumps and nozzles. Proper nozzle, pump, and filter selection is important.

Tunnel ventilation is another option that increases airflow, improves environmental conditions, and reduces heat stress. In this system, large fans (4-6 feet) are used to move air through a barn at an air speed of 400-600 feet per minute, which is fast enough to provide a beneficial wind chill effect that cools the cows by convection. The entire air passage is located on one end wall of the barn with all of the exhaust fans located on the opposite end.

\section{Summary}

If optimum production is to be achieved in Florida, dairy cows must be provided with relief from heat and humidity. Several methods are available for doing this. The most cost-effective is the use of shade structures. Supplemental cooling will provide additional benefits, especially when it is used at points of high heat stress, such as feed barns and loading and holding areas. The cooling system that has the widest application in Florida is sprinkling combined with fans. Long-term monitoring of cows and facilities results in identification of opportunities to improve cooling strategies to alleviate heat stress and to prevent possible negative effects. 